\title{
FORMAR PSICÓLOGOS: POR QUÊ? PARA QUÊ?
}

\author{
Jurema Barros Dantas $\star$
}

\begin{abstract}
Resumo
Este artigo elucida duas questões centrais: a primeira se debruça sobre a necessidade em se formar psicólogos e a segunda procura entender o para que de tal formação, relacionando ambas às questões com nosso momento histórico, na tentativa de refletir sobre esta formação que, ainda hoje, se encontra por vezes atrelada somente à noção de especialista. Queremos discutir uma formação de profissionais que por vezes se configuram como meros reprodutores de conceitos e técnicas destituidos da História e, para isso, colocaremos em cena uma formação psi que, comprometida socialmente, prioriza o humano, reiterando no ato de viver o caráter pleno de luta política e o da afirmação de modos singulares de existir.

Palavras-chave: formação; psicologia; educação; contemporaneidade.

\section{TO FORM PSYCHOLOGISTS: FOR WHAT? WHY?}

Abstract

This article illuminates two central issues: the first focuses on the necessity to train psychologists and the second seeks to understand that such training, relating to issues with both our historical moment, trying to think about this training, even today, is only sometimes linked the notion of specialist. We want to discuss training of professionals who are sometimes depicted as mere breeding concepts and techniques devoid of history and, therefore, put in a training scene that psi, socially committed, prioritizes the human and reiterated in the act of living full of character political struggle and the affirmation of natural modes to exist.
\end{abstract}

keywords: formation; psychology; education; nowadays.

\footnotetext{
^ Psicóloga, doutora em Psicologia Social pela Universidade do Estado do Rio de Janeiro, Mestre na área de Estudos da Subjetividade pela Universidade Federal Fluminense, Especialista em Psicologia Clínica pelo Instituto de Psicologia Fenomenológico - Existencial do Rio de Janeiro, Pesquisadora Capes na área de Filosofia e Clínica. Endereço: Universidade Veiga de Almeida, Centro de Ciencias Humanas Letras e Artes. Rua Ibituruna, 108 - Tijuca. Rio de Janeiro, RJ Brasil. CEP: 20520-200.

E-mail: juremadantas@ig.com.br
} 


\section{INTRODUÇ̃̃o}

As condições políticas são o solo em que se formam o sujeito, os domínios de saber e as relações com a verdade. A própria verdade tem uma história (FOUCAULT, 1999).

Este artigo pretende ser uma reflexão sobre o porquê formamos psicólogos e, sobretudo, para que realizamos tal formação, na tentativa de buscar um repensar sobre elas: a que demandas atendem e ao mesmo tempo produzem, e quais foram algumas de suas gêneses históricas. Não temos a pretensão de realizar um panorama histórico do surgimento da Psicologia e do seu vasto campo de conhecimento. Nosso propósito é um tanto humilde na busca de refletir sobre a formação e a prática psicológica na contemporaneidade. Para tanto tentaremos aproximar primariamente a Psicologia enquanto prática histórica. Neste trabalho pretendemos de forma audaciosa apontar a relevância desta temática não apenas para o campo "psi", mas para todos aqueles que ensinam e que, como qualquer outro dispositivo social são responsáveis pela produção de subjetividades. Em última análise, queremos discutir os chamados especialistas e a produção de verdades competentes.

Para tão audaciosa missão faz-se necessário uma discussão, ainda que breve, sobre o "por que" formar psicólogos, trazendo contribuições de outras áreas do conhecimento no sentido de situar essa categoria profissional na modernidade e seu mandato social. Em que consiste nosso trabalho? Qual o limite entre uma formação e uma articulação concreta de movimentos de usina produtora de sentidos heterogêneos do humano? Todas as práticas psicológicas estão essencialmente comprometidas com o social? A formação psicológica serve ao social de que modo? Com que finalidade?

Essas serão apenas algumas indagações que tentaremos explorar ao longo deste ensaio onde claramente pensaremos a formação em Psicologia do ponto de vista de uma perspectiva política e crítica, pois acreditamos que pensar a formação do ponto de vista da relação ciência e técnica acaba nos remetendo a uma perspectiva positivista e reificadora onde as pessoas que trabalham com Psicologia são vistas como sujeitos técnicos que aplicam com maior ou menor eficácia as diversas tecnologias psicológicas produzidas pelos cientistas e especialistas na área. Toda prática psicológica envolve uma prática política, contudo, que contornos de prática são esses, que horizontes eles alimentam ou consideram ajudar? Muitas vezes as práticas "psi" imbuídas do honroso compromisso com a sociedade acabam por alimentar práticas vigentes consideradas "verdadeiras". $\mathrm{Na}$ perspectiva política, que abraçamos neste texto, estas mesmas pessoas aparecem como sujeitos críticos que, armados de distintas estratégias reflexivas, se comprometem, com maior ou menor êxito, com práticas psicológicas e educativas concebidas na maioria das vezes sob uma perspectiva política. Entendemos a formação em Psicologia como práxis embebida em compromisso social e não como uma simples ciência aplicada. Devemos estar atentos à nossa formação e, consequentemente, às nossas práticas que estão imersas em territórios caracte- 
rizados como competentes e detentores do saber sobre os processos humanos. Enquanto profissionais peritos, especialistas que detêm o saber científico, neutro, verdadeiro, universal, não podemos nos abster do fato que somos atravessados e constituídos por vetores e fatores históricos que não apenas influenciam como determinam nossos modos de agir, pensar e trabalhar.

Chegamos ao ponto de que toda prática psicológica bem como toda formação é um ato político entendendo o mesmo tanto como uma carência ou uma autêntica potência de uma prática psicológica envolvendo o humano. Cotidianamente, nossas práticas e nossos bancos escolares aceitam e endossam certas identidades ou receitas consideradas corretas e convenientes sobre a problemática humana. Essas práticas consideradas científicas e, por isso mesmo, percebidas como objetivas e neutras, produzidas pelos chamados especialistas são importantes e configuram essencialmente o conjunto a formação do profissional "psi", a nossa questão versa sobre o reducionismo de uma formação apenas pautada num conjunto de obras fechadas em si mesmas ditas verdadeiras que acreditam dar contar das questões que envolvem nossa subjetividade. A importância destas teorias e de suas benesses é notória e se consolida ao longo dos anos apenas devemos ter a atenção de problematizar as fronteiras de nossas ações, ou seja, tornas nossas práticas concretas além de qualquer bibliografia ou conceito científico. Precisamos tornar nossa prática centrada naquilo que há de verdadeiramente humano: um efetivo exercício da cidadania. Faremos isso quando sairmos deste lugar de saber verdadeiro e nos colocarmos como formadores de opiniões, como pensadores do humano, como pensadores de nossas próprias práticas procurando desnaturalizar os discursos acerca do homem e do mundo.

\section{A Formação em Psicologia como uma prática política}

Penso que para que possamos nos implicar um pouco mais efetivamente com algumas transformações temos que começar a colocar em análise esse lugar saber-poder que ocupamos. Para tal, é com nossas próprias práticas que poderemos desnaturalizar as "verdades" que nos aprisionam, as dicotomias e binarismos que ajudamos a construir em nosso cotidiano (COIMBRA, 2003, p. 14).

Queremos pensar como a Psicologia enquanto formação e, neste aspecto, estando totalmente envolvida com os paradigmas educacionais, vem criando e fortalecendo alguns territórios e, conseqüentemente, produzindo e reproduzindo modelos. Os modelos teóricos tão caros e essenciais à Psicologia devem e merecem ser lembrados bem como referenciados qualitativamente e historicamente como marcos de respaldo científico e epistemológico. Este mérito e este lugar temporalmente construído não serão colocados em questão apenas tentaremos ampliar nosso olhar tentando pensar sobre os lugares da psicologia nos dias de hoje enquanto práticas que são produzidas e estão, cotidianamente, atravessadas pela história, por fatos cotidianos e não apenas por elucubrações filosóficas. 
Ainda que tenhamos um legado cientificamente comprovado e sólido, acreditamos que não são lugares neutros, a - históricos estes que são ocupados pela psicologia hoje. Se a formação em Psicologia atende uma configuração sócio-histórica marcada e datada, em que momentos podemos encontrar algo de novo e criativo que venha afirmar outras percepções, outros modos de ser e de estar no mundo? Considerando que toda prática psicológica é histórica e datada nossa indagação se desloca para pensar em que momento podemos nos indagar sobre o modo como formamos os psicólogos e o que queremos com isso? Formamos psicólogos capazes de reflexão sobre o seu cotidiano? Reflexão sobre que práticas produzem ou que resultados promovem? Como pensar a formação sem

[...] denunciar o caráter anti-natural desses especialismos que trazem para o corpo social, dentre outros efeitos, o não saber sobre o que se produz, para que se produz e que funções tem essa produção em nossa sociedade? (COIMBRA, 2001, p. 87).

Nosso propósito é questionar uma possibilidade de formação "psi" onde se luta cotidianamente no sentido de se afirmar caminhos diferentes dos modelados pela "mídia" e demais equipamentos coletivos ainda que estes se encontrem aferrados nos sólidos espaços acadêmicos. Teorias, técnicas, compreensões e explicações diversas sobre o homem são necessárias, pois se configuram como uma das bases de nossa formação "psi”. A questão que se apresenta neste ensaio é exatamente o que estas teorias nos desvelam, o que elas promovem e o que elas reproduzem em nossas práticas cotidianas. O quanto estas teorias acabam prisioneiras em formar apenas os especialistas, em transmitir conceitos essenciais à formação sem, contudo implicá-los no contexto histórico da contemporaneidade. Será que no cotidiano estamos falando de interiores subjetivos fechados em si mesmos ou de cidadania, de sujeitos psíquicos com questões concretas que diariamente nos vem ao encontro. Teoria e pratica são conjuntas e atravessadas por isto mesmo se torna fundamental a discussão de uma prática política no aspecto do respeito ao sujeito que nos procura. Respeito que não se aprisiona num diagnóstico ou num número de prontuário. Mas respeito que se configura em prática de escuta e ação. Que se configura numa prática política não reprodutora de especialismos, mas reprodutora de uma reflexão de nossas ações no mundo.

$\mathrm{Na}$ verdade queremos convidar o leitor a navegarar conosco numa discussão sobre esses espaços na Psicologia onde possamos refletir sobre esta formação tecnicista e especialista, que corrobora com algumas demandas da contemporaneidade esquecendo que

[...] as verdades são produções histórico-sociais e que nós, os intelectuais, cientistas, pesquisadores, especialista, peritos, somos uma parcela importante daqueles que, ao longo do tempo, têm tido tal tarefa: a de produzir verdades. Verdades consideradas como "científicas" e, portanto, neutras, objetivas, absolutas e universais (COIMBRA, 2002, p. 03). 
Esquecendo que nossos males existenciais estão sendo, no alarido da modernidade, continuamente individualizados, familiarizados e psicologizados. Nosso tecido social aos poucos psicologiza a vida, escraviza seus atravessamentos históricos e políticos e, por fim, transforma as relações de poder em relações psicológico-existenciais que devem ser tratadas e curadas. Colocar em discussão estas produções hegemônicas em nosso mundo e no âmbito das universidades significa entender esses objetos, assim como o fez Foucault (1988), como não tendo existência em si, como não naturais, mas sendo encapsulados historicamente por práticas que os objetivam e que são muito bem datadas. Nossas práticas, nossos alunos, nossas universidades, nossos sujeitos não são dados em si, nem existentes por si, mas estão continuamente sendo produzidos por práticas como um artesanato jamais completado. Assim, estamos falando do real pela via da história. Estamos falando da formação em Psicologia pela via da história. Uma história onde currículo, sistemas e técnicas psicológicas são imprescindíveis, mas se apresentam apenas como um das faces desta formação que, essencialmente, precisa ser contextualizada, política, cultural e socialmente como possibilidade de uma prática enriquecedora do seu tempo.

A formação do psicólogo estando atravessada pela história e pelos panoramas de nosso tempo não deve se tornar um dispositivo político que intimiza a vida ou que dicotomiza o humano em antagônicos espaços de acordo com suas supostas "capacidades ou potencialidades".

São, portanto, nossas próprias práticas que têm produzido os saberes da Psicologia como "científicos", "neutros", objetivos" e a Política como outro mundo, de onde o psicólogo enquanto profissional está excluído, pois é o território da militância, por excelência (COIMBRA, 2001, p. 86).

Estes territórios impermeáveis e sedentários, desprovidos da política e da história, que estão presentes em nossa trajetória "psi", apenas inviabilizam estratégias de escape ou de fuga de formas sufocantes e fechadas de se compreender a realidade. Mais uma vez, recorrendo a Foucault (1988) notamos que os saberes quando são compreendidos como materialidade, práticas e acontecimentos são vividos como dispositivos políticos articulados com todas as estruturas sociais. A psicologia se constitui no social, tem uma relação dialética com o social, produz o social, pensa o social e, por dever, precisa ter um compromisso com o social que só é possível mediante a ampliação da formação "psi" bem como dos diferentes domínios do saber. A formação em Psicologia deve ser um processo criativo de amplo conhecimento e descoberta onde o psicólogo não mais se configuraria apenas como um "especialista", mas sim, aquele que se propõe a pensar e, se possível, modificar as questões que envolvem a subjetividade.

Queremos engendrar entre os profissionais de psicologia indagações necessárias sobre sua importância no contexto social de produção de subjetividade e sobre sua implicação na prática e na investigação acerca do humano. Esta tarefa é árdua considerando que a educação, ou melhor, os processos de formação já se constituíam como um aparelho de normatização do indivíduo, como produção da 
subjetividade burguesa e vigente, tendo como função uníssona à homogeneização e o disciplinamento da diversidade sócio-política que se desvelava ao longo da história da nossa sociedade. Será que em pleno século XXI, conseguimos nos nossos bancos escolares a diferença, a heterogeneidade como expressões de aspectos próprios da existência? Ou será que continuamos passando conteúdos estanques por vezes distantes das realidades vivenciadas pelos nossos alunos. Sendo assim, não é muito difícil aproximar a formação psicológica da formação da cidadania, pois acreditamos que ser psicólogo e ser cidadão se caracterizam por serem participativos, conscientes e responsáveis. Este poderia ser o imperativo universitário.

As teorias, os estágios, as supervisões não excluem a política pelo contrário, alimentam, fortalecem e questionam possíveis atuações diferenciadas e preocupadas com o conjunto social e não com o desviante, ou melhor, com aquele que se mostra a margem do processo. Isto porque o desvio e a margem nada mais são do que retratos desta formação e desta compreensão homogênea do especialista. Ao falarmos da relevância do por que e do para que formar psicólogos queremos ampliar a questão da formação de um lugar com livros e técnicas para um lugar de análise permanente que crie um vínculo originário e indissolúvel entre formação e sociedade.

Com isso queremos nos contrapor, a uma formação "psi” que em geral, traz certas características modelares instituídas e bem marcadas; como, um certo predomínio do viés positivista, onde se tornam hegemônicos os conceitos de neutralidade, objetividade, cientificidade e tecnicismo; onde, nos diferentes discursos e práticas, o homem e a sociedade são apresentados como "coisas em si", abstratos, naturais e não produzidos historicamente.

Não queremos, com todos os comentários realizados anteriormente, colocar em cena discussões sobre estágios, carga horária de disciplinas ou estruturas curriculares. O que entendemos, quando colocamos a formação "psi”" em estudo, é que se a discussão vai por estes tão bem conhecidos caminhos acaba por deixar de lado certos atalhos fundamentais que coloquem a própria formação em questão. Pensar a formação é apresentar um território teórico necessário casado com uma formação crítica, reflexiva e política sobre si e sobre o mundo. Logo, se estamos nos propondo a pensar a formação "psi", tenhamos claro que esta não será aqui entendida como este acumulado material desconectado, tornado abstrato e com anseios de se tornar mercadoria pelos profissionais especializados no comportamento ou no bom trato das emoções. Pelo contrário, é o sentido ativo, de produção de efeitos, que se resgata quando tomamos a formação como processo, cruzamento de linhas de forças e produção apenas de territórios provisórios. Territórios que possibilitem ao aluno a discussão das transformações aceleradas de nossa época, no novo que já nasce obsoleto, da profusão de informações, da fragilidade dos laços humanos, da busca pela felicidade artificial ou da "era do vazio que parece ter se instalado definitivamente nas institui8ções de educação" (SOUZA, 2001, p. 285).

Partindo destas colocações, deparamo-nos com uma evidência. Nesta formação datada, o dia-a-dia exposto nos jornais não pode mais ser abafado nas salas de aula dos cursos de psicologia. Fala-se em justiça social, no oprimido, mas nossas práticas cada vez mais compactuam com as violências simbólicas e 
concretas. Compactua-se através do silêncio das discussões não promovidas com diversos debates, compactua-se com os planos de aula muito bem definidos e, sobretudo, através do título de especialista. E como continuidade da atuação profissional isso aparece através de atos de amor ao próximo, um próximo sem rosto, sem cheiro, sem cor ou país. Um próximo que é mais um número em nossa escala de testes psicológicos ou mais um nome num plantão de serviço de psicologia aplicada. Nossa formação modulada se fecha a conhecer o outro. Nossa formação técnica se fecha a indagar seus instrumentos e seus alcances. Não podemos construir um saber sem os paratos tpecnicos bem como os médicos necessitam dos remédiso mas será que tudo é doença, será que toda forma de estar com o outro deve passar por uma técnica muito bem explicada e montado onde a nossa única preocupação são os passos a seguir? É fundamental que sejamos apenas técnicos? Que demandas atendemos, fortalecemos ou produzimos nesta formação que se coloca por vezes a margem das discussões sociais?

Como tais demandas não são naturais, eternas e neutras; ao contrário são produzidas historicamente, datadas e localizáveis e, sobretudo, fortalecem subjetividades hegemônicas produzidas em nossa sociedade, pensamos que é importante ressaltar que as práticas que, por vezes, estão sendo fortalecidas nos meios acadêmicos realimentam, muitas vezes, de modo geral e acrítico, as demandas que nos são apresentadas pelo campo social, como necessárias e espontâneas.

Esses discursos e práticas "competentes" enunciados pelos especialistas forjam a todo o momento onde estão as verdades: o bom cidadão, o bom pai, o bom filho, o bom aluno, entre outros (COIMBRA, 2001, p. 86).

O importante na questão que envolve o porque formar profissionais bem treinados e tecnicamente qualificados para o exercício da profissão geralmente envolve campos teóricos que são repassados como "verdades" a serem seguidas. Verdades sagradas e inquestionáveis. Neste momento, preso nessas amarras, o saber perde sua vitalidade exatamente naquilo que de novo ele poderia produzir. Tanto as técnicas como as teorias não são percebidas como produções históricas de sentido, mas sim, como dogmas que devem ser seguidos biblicamente. $\mathrm{E}$, assim, não conseguimos avaliar os efeitos cotidianos que nossas práticas estão produzindo no mundo e não entendemos as técnicas e teorias que nos são apresentados como instrumentos. Percebemos, ainda que sutilmente, os meios acadêmicos transformam esses instrumentos em modismo, em "verdades" prontas e acabadas. Tais instrumentos tornam-se, então, instituições inquestionáveis e apenas reproduzíveis. Este, a nosso ver, é o grande desafio do por que formar psicólogos: desnaturalizar práticas que, rotineiramente, vem sendo produzidas como naturais, eternas e necessárias.

A cada momento, em nossas práticas profissionais, o Brasil é diluído de suas contradições. Nos fazem crer, segundo Branco (2001, p. 167), que somos os únicos intelectuais capazes de pensar, intervir e transformar a realidade. $\mathrm{Na}$ exclusão do dia-a-dia, nossa formação nos faz construir formas pré-estabelecidas de ser e de viver. Nosso pensamento se reduz a julgar ou recolocar alguém em seu 
"percurso normal", o cotidiano costumeiramente não nos surpreende mais, pelo contrário, nos paralisa e produz práticas indutoras de inércia. Contudo, queremos entender este cotidiano como uma encruzilhada indicadora de múltiplas possibilidades. Um cotidiano inquietante que, possivelmente, nos interrogue sobre aquilo que nos é mais familiar: nossas práticas e saberes.

Baptista (2000) deu à formação do psicólogo o nome de fábrica por acreditar que este lugar de formação é um lugar de alienações e contradições promissoras. Segundo o autor:

Pensar a formação do psicólogo como fábrica não solicita somente críticas ou cobranças a sua estrutura. Incluí-la na engrenagem fabril estaria na possibilidade de detectarmos sua produção de vida e morte ou, em outras palavras, produção de homens-estojo e de atiradores de pedra (BAPTISTA, 2000, p. 18).

Essas fábricas, de acordo com Baptista, possuem uma razão ou motor para seu funcionamento, apresentam um processo que a concretiza e, essencialmente, produzem algo. O caminho percorrido por cada sessão desta fábrica é o ponto central deste artigo na medida em que buscamos pensar a construção sócio-histórica do saber/fazer psicológico, suas contradições geradoras de indagações e, fundamentalmente, outras propostas que possam viabilizar uma forma diferenciada de apropriação da formação "psi” em questão. Formação esta que em sua fábrica possui:

[...] uma chaminé que leva as nuvens de fumaça para longe da fábrica, invadindo a cidade e ocupando outros lugares. O cotidiano fabril adere em vários espaços. Penetra em corpos e afetos. Penetra na Baixada fluminense, nas igrejas, em táxis e elevadores. Poluindo ou sinalizando a presença da potente destruição (BAPTISTA, 2000, p. 19).

\section{A Formação em Psicologia e o cenário atual}

Ao discutir o saber e o fazer psicológicos, acompanhando as transformações e exigências sociais do mundo contemporâneo, buscamos constituir um lugar político e efetivamente participante na construção de estratégias de reconhecimento do trabalho da psicologia nesse contexto social. Propomo-nos a puxar uma linha do novelo, no emaranhado de relações singulares e institucionais de nosso cotidiano acadêmico.

Gradualmente somos convocados a dar conta de solitários e solidários da exclusão que se multiplicam e se misturam no mundo da globalização, da velocidade e do consumo. A ebulição social na contemporaneidade aponta, a todo o momento, a demanda psicológica. A questão é como temos dado conta dessa efervescência. Ao permanecemos orientados por um modelo de Psicologia que se centra no diagnóstico, na norma, no ajuste, na aplicação da técnica como fi- 
nalidade, não encontramos as demandas, nem produzimos as ofertas, passamos por elas. Não lidamos com o humano lidamos com um objeto de estudo a ser quantificado, calculado e rotulado.

A modernidade se caracterizou pelos estudos metafísicos e pela sistematização e valorização da ciência como modos de se alcançar a verdade, as certezas e os invariantes universais capazes de explicar e controlar toda a natureza, inclusive a natureza humana (FEIJOO, 2001, p. 177).

Esta é a nossa modernidade onde acelera-se o tempo, o consumo passa a ser a ordem do dia, as comunicações agora se fazem em tempo real, as inovações tecnológicas deixam suas marcas e benefícios. Bancos eletrônicos, dinheiro de plástico, técnicas para proporcionar juventude eterna, viagens ao espaço. Há uma gradativa compressão do tempo e do espaço. Os serviços, os conhecimentos e as próprias relações humanas são efêmeras. Vemos uma acentuada volatilidade e efemeridade das modas, dos produtos apresentados pelo mercado, das técnicas de produção e dos processos de trabalho.

Que formas de pensar, sentir e agir estão sendo alimentados e forjados por nossa sociedade? Enfatizam-se os valores e as virtudes da instantaneidade, da descartabilidade, da diversificação, do planejamento e ganhos de curto prazo. Manipula-se gostos e opiniões através da construção de novos sistemas de signos e imagens. Nossa sociedade é o universo da extrema mobilidade do capital, do consumo, onde tudo é fragmentado, instantâneo e volátil.

Coimbra (1995) refere-se a esta tendência de parâmetros de objetividade, determinismos e verdades inquestionáveis como uma tendência a "psicologização e os especialismos psi" onde há uma nítida rejeição pelos movimentos políticos e sociais em busca de um projeto individual de ascensão social, sucesso profissional, equilíbrio familiar. Em outras palavras, a Psicologia com seus especialismos forneceu uma "legitimação científica à tecnologia do ajustamento". Dentre estes técnicos especializados ou os mestres da auto-ajuda, estamos nós psicólogos. Nós que, com um emaranhado de práticas, consideradas competentes e objetivas, produzimos, reproduzimos ou, por vezes, fortalecemos esses modos de vida, de sentir, pensar e agir. Nós, os especialistas "psi", temos sido formados, na maior parte das vezes, para mantermos a ordem e o suposto "equilíbrio" social. Sentimo-nos desconfortáveis e questionamos com prontidão as críticas direcionadas à nossa identidade profissional quando na realidade o que nos amedronta é o não-saber diante dos intensos dilemas existenciais de nossa vida contemporânea. Que diálogo temos estabelecido com as práticas "psi” contemporâneas?

$\mathrm{Na}$ realidade devemos historicizar todos esses saberes que nos são impostos como naturais e eternos e, devemos, sobretudo, questionar o cômodo lugar por nós ocupado no mundo capitalístico, ${ }^{1}$ como o lugar do saber científico e objetivo.

Ao problematizar a formação do psicólogo queremos entender o nosso fazer como algo orientado pela multiplicidade, num campo de interfaces entre disciplinas, numa busca permanente que rompe com os modelos naturalizados. 
Construímos o sentido de nosso fazer, à medida que nos permitimos experimentar outros modos de formar/ensinar no andar pela vida com os sujeitos. O que define a práxis não é somente a tarefa - pesquisa, conhecimento, intervenção -, mas também os pressupostos e intencionalidades de quem a executa, ou seja, uma práxis é mediada pelo sujeito da ética. ${ }^{2}$

Nossa reflexão vai ao encontro de Barros (1995) que, ao debater sobre a formação dos psicólogos, coloca a própria instituição de formação em questão, desnaturalizando-a a cada momento que se cristalize e que se ponha a falar como lugar de verdade, pois considera que quando não compreendemos as relações que configuram as diversas práticas, as transformamos em leis a serem cumpridas. A autora analisa a formação dos "psi”" como uma instituição que deve escapar dos planos hierarquizantes onde o conhecimento esteja desvinculado das relações de poder que o configuram. Percebemos, assim, que a formação "psi" se apresenta como um universo homogêneo e desarticulado de superficialidades, como um sistema fechado e avesso a novas produções. Vemos um saber que, tacitamente, dicotimiza a prática da teoria, neutraliza ações de rebeldia, produz papéis previamente definidos e promove efeitos normatizadores de poder. Colocar em questão a formação não passa pela busca de uma identidade ou de um papel para o psicólogo, passa pela invenção de outros modos de subjetivação que rompam as amarras hermeticamente instituídas no campo "psi”.

Todo nosso problema de investigação está muito bem colocado no prefácio do livro de Baptista (2000), quando Jurandir Freire Costa apresenta que a questão é a de:

[...] mostrar como certas crenças criam sujeitos à imagem e semelhança de seus princípios, injunções ou formas de vida. E quando tais crenças são chamadas científicas, os praticantes ou crentes dificilmente podem aceitar a idéia de que o modo de suas leituras dos fatos são pressupostos ético-políticos e não evidências compulsórias, determinadas pela "verdadeira natureza das coisas e eventos do mundo". Assim, a prática do psicólogo não mais busca redescrever os sujeitos com vistas a uma vida melhor e mais humana; tende a tornar-se um manual de rotinas de atitudes e protocolos de investigação, sem vínculo com a criatividade, a variabilidade e a imprevisibilidade da vida (COSTA, 2000, p. 5).

Queremos com estas reflexões mostrar que um compromisso com a ética do humano pode poupar-nos do risco de um tecnicismo sem limites ou fundamento. Tecnicismo que, na maior parte das vezes, corta a existência de seus elos com os outros e com o mundo a fim de configurá-la, posteriormente, como uma existência sem sentido, sem futuro, sem mundo e sem parceria. Buscamos neste artigo, justamente, a construção minuciosa e cuidadosa de outra forma de pensar o porquê e o para que a formação psicológica. Uma forma de pensar que tenha como princípio o fato de que atendemos pessoas e não prontuários, somos pesqui- 
sadores e não especialistas normativos somos historiadores e não técnicos. Não podemos despotencializar nossa intervenção, nos legando o papel de espectadores numa situação onde somos os protagonistas da história.

Essas reflexões que aqui se seguem ampliam a discussão da formação e seus princípios. Estamos convidando a partilhar de nossa discussão apenas aqueles que ousarem a libertar-se do imediatismo do fazer psicológico e se propuserem a superar o incômodo de caminhar sem apoio e por suas próprias pernas. No contemporâneo confinamos a questão da Psicologia às universidades. Há um setor ou instituição que se encarrega dela. Desenvolvemos mesmo ciências que acreditamos, particularmente, orientarem melhor determinados tipos de Psicologia Aplicada sem contar com seus inúmeros desdobramentos. Ao delegar as reflexões sobre a Psicologia somente ao campo acadêmico acabamos por perder de vista a própria Psicologia. Uma Psicologia que pode e deve se configurar como prática e como uma ação permanente. A Psicologia tem sido tomada como uma "tarefa" a ser concretizada ou um processo contínuo de obtenção de informação. Demos a ela outro e especial atributo - o ser "técnica". Nossa preocupação é com o aparato técnico e seus resultados. Na nossa contemporaneidade parece não haver espaço para Psicologia enquanto processo histórico apenas para o aparato técnico. Aquilo que na técnica se manifesta como seu constitutivo básico são os processos, conteúdos, instrumentos, recursos, objetos e objetivos bem definidos. Não que esses fatores não sejam importantes, contudo, não devemos restringir a formação do psicólogo, a uma mera aquisição de fazeres técnicos que possibilita o exercício de uma profissão.

Talvez o saber/fazer psicológico resida exatamente na compreensão de seus atravessamentos sócio-históricos, bem como nas redes de relação que se estabelece entre os atores deste processo de formação, que tem algo de técnico, mas, é essencialmente, humano. É nesse modo básico e habitual de ser que a psicologia encontra sua verdadeira morada. Isto porque não queremos forjar uma psicologia especialista que está fora do seu tempo. Queremos pensar a formação psicológica como um ser, um corpo subjetivo, político, intelectual, visivelmente implicado com a sociedade a que pertence, suas problemáticas e seus limites. Queremos pensar as potencialidades de diálogo do discurso psicológico com a cultura contemporânea.

Neste momento podemos pensar em Walter Benjamin (1987) que nos diz que, para entender a subjetividade nas suas perdas e ganhos envolvidos, não devemos compreender a história como movimento contínuo e linear, mas marcada por rupturas, apontando assim para a possibilidade de tudo ser diferente do que efetivamente é; entendemos que a Psicologia é uma prática política social que reconhece os coletivos como forças do contemporâneo, forças que concorrem para a produção daquilo que chamamos de formação em psicologia. A história não é um lugar homogêneo, mas sim, composta de diferentes vozes, podendo sempre reverter o estabelecido, o institucionalizado, escovando a história a contrapelo, interferindo nos caminhos de seu tempo. Assim, apesar de todo processo de laminação que tem sofrido a subjetividade, e a própria Psicologia, tais mecanismos podem ser utilizados como possibilidade de singularização ou processo de criação. 
Asssim, devemos constituir um saber ou prática implicados socialmente para não corrermos o risco de reduzir a complexidade do trabalho em Psicologia a uma questão individual. Esta lógica individual traz consigo a idéia de culpa que apenas auxilia a estagnação das engrenagens educacionais. Engrenagens que devem ter como combustível a relativização dos saberes, a indagação quanto às perigosas generalizações e prescrições que freqüentemente encontramos na atuação do psicólogo.

Estas generalizações apenas admitem que o nosso corpo de conhecimento, tradicionalmente construído na formação universitária, não dá conta da complexidade que o contemporâneo nos coloca e, que, via de regra, é a concepção de que o trabalho do psicólogo é colocar as coisas que estão fora do lugar em seu eixo adequado. Evidentemente, esta concepção, gera desconforto, indica a prepotência de um saber que está além da história, que se dinamiza por conta própria, que não se interroga sobre seu tempo e que, acredita, que pela via da ação ortopédica podemos colocar qualquer coisa no seu devido lugar.

O desafio que nos resta é abandonar o lugar frágil e ilusório de que sabemos muito e admitirmos o não saber, a precariedade do nosso corpo de conhecimento e a necessidade de constituírem-se novas formas de trabalho, novas posturas em defesa dos ideais que permeiam uma ética na Psicologia.

Se pensar a Psicologia nos coloca, inevitavelmente, a tarefa de repensarmos as configurações de nosso tempo que formam a tessitura do corpo social em que vivemos, que este exercício seja feito rápida e eticamente, em busca de um trabalho sério e com compromisso social.

A Psicologia deve preocupar-se em constituir, no campo de sua formação, o entendimento e a crítica ao modo como a sociedade está organizada, indicando quais os fatores que favorecem e os que não favorecem a obtenção da igualdade de direitos dos cidadãos, fazendo incidir essa crítica dentro do âmbito da própria formação, ou seja, a idéia é propor a construção de saberes afinados com o comprometimento social, buscando proposições de políticas que engendrem uma mudança possível. Aqui não há mais informação a ser transmitida, mas provocações a novas invenções, criação de outros mundos.

A Psicologia precisa sofrer um processo de abertura aos problemas da sociedade, precisa ser sensível a eles, propondo interpretações e respostas possíveis ao seu enfrentamento, precisa democratizar o saber, torná-lo acessível e compô-lo alinhado com as questões sociais. Seria uma maneira possível de juntar forças, conjugar o conhecimento de outras formas, minimizar a precarização que as instituições vêm sofrendo, pelo menos no material mais importante que é a questão da formação das pessoas.

Estamos querendo sinalizar o nosso franco processo de rupturas com modelos determinantes que dizem como o sujeito deve ser, o que deve fazer ou pensar. Queremos no âmbito da Psicologia uma dialética social que sensibilize a formação do psicólogo não como um mero especialista, mas sim, como um profissional que, acompanhando as mudanças de seu tempo, promove uma prática crítica e relevante socialmente. Em síntese, podemos dizer que queremos construir no lugar do especialista que, na maioria das vezes, responde de um lugar 
que corrobora com essas intensidades do mundo contemporâneo, um lugar de aprendiz em formação permanente que criticamente analisa o contexto no qual se insere interrogando a sua própria prática: seus princípios e objetivos.

\section{Considerações Finais}

Ao questionar-se sobre o que seria ensinar para um novo estilo de fazer Psicologia, Kastrup (1999) aponta como alternativa de produzir, com o estudante, uma política de invenção na qual se mantém vivo o aprender a aprender, em que o saber transmitido não se separa de repetidas problematizações. A autora destaca que a invenção não opera sob o signo da instantaneidade, implica uma duração, um trabalho com restos, uma preparação que ocorre no avesso dos planos visíveis. É uma prática do tateio e de experimentação, composição e recomposição incessante.

Muitos movimentos, e neles incluímos a Psicologia, devem ser operados neste processo de constituir a formação por outras formas e modos de trabalhar e subjetivar. Queremos tencionar movimentos de ruptura, buscando ir além das propostas convencionais que, muitas vezes, fazem da formação profissional um simples preparatório - por vezes falho- para inserção no mercado de trabalho. Queremos instigar outras formas de pensar, que busquem atender as múltiplas maneiras do ser humano se constituir e produzir saberes e práticas ligadas às especificidades de cada campo de atuação.

A formação na Psicologia implica um compromisso de ir além do cumprimento de etapas curriculares e da busca de um lugar profissional no mercado, para se colocar como agente social, construindo e sendo construído pelo processo em curso. Mais uma vez podemos citar Kastrup (1999, p. 204):

A prática profissional não pode fazer com que se perca a condição de aprendiz. A formação e a aplicação não são dois momentos sucessivos, mas devem coexistir sempre. Resta, a todo aquele que se encontra concernido com a Psicologia, atuar como um aprendiz-artista, mantendo, em sua prática diária, a tensão permanente entre problematização e a ação.

Ser aprendiz é nunca falar de um lugar de verdade absoluta e ao estabelecermos uma nova relação com a técnica e com a formação estabelecemos uma nova relação com o humano. Concordamos com Santos (1996) no que diz respeito a um projeto educativo emancipatório, cuja aprendizagem da conflitualidade dos conhecimentos tem de ser ela própria conflituosa. Temos então um campo de possibilidades de conhecimento atravessado não exclusivamente por idéias, mas sim, por emoções, paixões e ideais que conferem a nossa prática um sentido inesgotável.

O nosso papel e a nossa função, nesse amplo horizonte, é a permanente reflexão acerca da Psicologia em seus limites e possibilidades. Mais do que nunca, hoje, não podemos abdicar da nossa possibilidade de realizar, de nos renovarmos com consciência nas situações concretas com as quais lidamos, de ressignificar a nossa vida. O que existe, de fato, são nossos dilemas no presente. Para enfrentálos há que abrir mão da formação idealizada, das representações que temos sobre 
nossa própria importância e optar existencialmente pela Psicologia. Resta-nos perguntarmo-nos se estamos decididos a abraçá-la com as nossas possibilidades e com as nossas limitações, e também com os nossos sonhos, a nossa esperança, a nossa indignação contra a miséria e a corrupção, a nossa vontade de humanizar a sociedade e reinventar esse país.

Sendo o humano o ponto de preocupação da formação "psi", os psicólogos têm na sensibilidade o motor de suas práticas e identidades. Contudo, a sensibilidade como dom individual, apropria-se de técnicas e teorias ofuscando sua materialidade. Quando incluímos esta mesma sensibilidade na História, temos a oportunidade de desconfiarmos de sua pureza e universalidade detectando seus agenciamentos. A materialidade desse conceito permite-nos retirar de cena corações e mentes protagonizando práticas e identidades. Remetendo-o à História, percebemos seu movimento entre homens, suas necessidades antagônicas e relações de poder. Podemos discutir sobre formação, mas jamais prescrever o que seria uma formação. A nossa contribuição se restringe a questionar determinadas formações "psi" que distanciadas da História se agarram em posições absolutas ou cartilhas de comportamento.

No que concerne à Psicologia ela cumprirá bem o seu papel se for capaz de ver o humano no lugar de um prontuário, se for capaz de se perceber implicada historicamente, se for capaz de entender que é produtora de práticas do mesmo modo que é produzida por elas. A formação "psi" deve encontrar morada numa reflexão permanente sobre a dinâmica social, interpelando os saberes cristalizados das abordagens psicológicas tradicionais.

À guisa de conclusão queremos sinalizar a possibilidade de uma formação pautada tanto numa postura inquiridora quanto num olhar investigativo que venha influenciar as práticas psicológicas de um modo geral. Repensar a formação é repensar a própria prática de Psicologia na atualidade o que nos leva à importância e urgência desta temática.

\section{Notas}

${ }^{1}$ O termo capitalístico, utilizado por Guattari, (GUATTARI; ROLNIK, 1988, 15-40)? “[...] designa não apenas as sociedades conhecidas como capitalistas, mas também setores do terceiro mundo ou do capitalismo periférico, assim como as economias antes ditas socialistas". Segundo o autor a produção de subjetividade é mais importante do que qualquer outro tipo de produção visto que produzem esquemas dominantes de percepção do mundo.

${ }^{2}$ Ao mencionarmos a questão da ética nos inspiramos em Foucault (1984) onde o mesmo ressalta que há um trabalho ético que o sujeito efetua sobre si mesmo, não mais, ou não simplesmente, para tornar o seu comportamento adequado a uma regra dada, mas, principalmente, para tentar transformar a si mesmo em sujeito de sua própria conduta. 


\section{REFERÊNCIAS}

BAPTISTA, L. A Fábrica de Interiores: a formação psi em questão. Niterói: EdUFF, 2000.

BARROS, R. D. B. A Formação dos psi: algumas questões sobre a ética. Revista do Departamento de Psicologia-UFF. Niterói, v. 7, n. 2 e 3, p. 4-9, 1995.

BENJAMIN, W. Magia e técnica: arte e política. São Paulo: Brasiliense, 1987.

BRANCO, G. C. As lutas pela autonomia e liberdade em Michel Foucault. In: SOARES, J. C.; EWALD, A. P.; DAMAS, C. (Org.). Anais das terças transdisciplinares: experimentando as fronteiras entre a Psicologia e outras práticas teóricas. Rio de Janeiro: Nappe/IP/UERJ/CRP, 2001. p. 165-175.

COIMBRA, C. M. B. Guardiães da Ordem : uma viagem pelas práticas psi no Brasil do milagre. Rio Janeiro: Oficina do Autor, 1995.

COIMBRA, C. M. B. Os especialistas da infância e da juventude: produzindo verdades competentes. Revista Paidéia, São Paulo, v.11, n. 20, p 85-88, 2001.

COIMBRA, C. M. B. Psicologia e Política: a produção de verdades competentes. 2002. Disponível em: <http://www.slab.uff.br/textos/texto67.pdf>. Acesso em: 13 jun. 2009.

COIMBRA, C. M. B. Das essências às multiplicidades: especialismo psi e produções de subjetividades. Psicologia \& Sociedade, Porto Alegre, v. 15, n. 2, p. 6-17, 2003.

COSTA, J. F. Prefácio. In: BAPTISTA, L. A. A Fábrica de Interiores: a formação psi em questão. Niterói: EdUFF, 2000. p. 5-8.

FEIJOO, A. M. C. Existencialismo, Psicologia e Sociedade. In: . Anais das Terças Transdisciplinares. Rio de Janeiro: EDUERJ, 2001. p. 177-192.

FOUCAULT, M. História da sexualidade: o uso dos prazeres. Rio de Janeiro: Graal, 1984. v. II.

FOUCAULT, M. Microfisica do Poder. Rio de Janeiro: Graal, 1988.

GUATTARI , F; ROLNIK, S. Micropolítica: cartografias do desejo. Rio de Janeiro: Vozes, 1988.

KASTRUP, V. A invenção de si e do mundo: uma introdução do tempo e do coletivo no estudo da cognição. São Paulo: Papirus, 1999. 
SANTOS, B. S. Para uma pedagogia do conflito. In: Reestruturação curricular: novos mapas culturais, novas perspectivas educacionais. Porto Alegre: Sulina, 1996. p. 76-87.

SOUZA, S. J. Educação na pós-modernidade: educar pra quê? In: . Anais das Terças Transdisciplinares. Rio de Janeiro: EDUERJ, 2001. p. 277-287.

Recebido em: setembro de 2009 Aceito em: setembro de 2010 